Tomasz OLSZOWSKI ${ }^{1}$

\title{
COMPARISON OF PM10 WASHOUT ON URBAN AND RURAL AREAS
}

\author{
PORÓWNANIE USUWANIA PM10 NA OBSZARACH MIASTA I WSI
}

\begin{abstract}
This paper reports the results of research into the effectiveness of scavenging of PM10, resulting from the occurrence of solid and liquid hydrometeors. The measurement campaign was undertaken over 7 years and involved the registration of PM10 in areas which have different aerosanitary conditions (i.e. urban and undeveloped rural area). The analysis involved 426 observations taken at constant time intervals of 0.5 hour. The measurements of the concentration of PM10 were performed by means of a reference method accompanied by concurrent registration of basic meteorological parameters. It was indicated that in a urban location, the intensity of the local emission sources is a principal factor influencing the value of mass concentration changes and the effectiveness of the dust scavenging that accompanies a given type of precipitation. It was also noted that for the same intensity of precipitation, only the deposition of convective rainfall and long-term large-scale precipitation do not lead to statistically relevant differences in the value of mass concentrations of dust for both areas. It was indicated that during solid and liquid frontal precipitation of light intensity $\left(<0.5 \mathrm{~mm} \cdot \mathrm{h}^{-1}\right)$, the effectiveness of PM10 removing is less in rural area. It was statistically proven that continuous precipitation of constant intensity and duration exceeding 2 hours has a similar effect of purifying the ambient air in both locations. The study revealed that short-term solid precipitation provides better characteristics of scavenging of PM10 compared with classic rainfall
\end{abstract}

Keywords: dust, PM10, snow, rain, removal coefficient

\section{Introduction}

Observations taken over many years indicate that the ability of the atmosphere to purify itself should be understood as the capacity of the atmosphere to capture solid and gas pollutants from the atmosphere by means of the forming clouds and precipitation in solid and liquid state $[1,2]$. Studies have reported that the scavenging of solid particles is more effective during in-cloud washout [3], Below-cloud washout is a more effective process for suspended particles with larger diameters [4-6]. In addition, since the process occurs close to the ground-level zone, wet deposition plays an important role in the transmission of pollution from the atmosphere into the ground. According to Chate et al. [7], wet below-cloud washout is one of the principal processes which ensure that a balance is maintained between the sources and removal of aerosol particles. Researchers in this area

\footnotetext{
${ }^{1}$ Department of Thermal Engineering and Industrial Facilities, Faculty of Mechanical Engineering, Opole University of Technology, ul. S. Mikołajczyka 5, 45-271 Opole, Poland, phone +48 774498457 , fax +48 7744999 24, email: t.olszowski@ po.opole.pl
} 
claim that this process can lead to scavenging of up to $30 \%$ of aerosols from the troposphere [8-10]. The process of purification of the below-cloud troposphere is described in terms of collisions between raindrops and aerosol particles [11]. Other mechanisms that play a role in this process, involving the effect of inertia, Brownian motion, thermophoresis, diffusophoresis, and electro-scavenging, are sufficiently recognized and described $[2,5,7$, 11-16].

The scavenging coefficient $\Lambda\left[\mathrm{s}^{-1}\right]$ is customarily used to explain the effectiveness of the self-purification of the atmosphere [17]. Due to the considerable number of factors which play a role in the below-cloud processes, scavenging coefficients are characterized with a considerable degree of variability [18]. The application of adequate parameters for description of their characteristics poses a current problem in the descriptions of climate models and models that deal with the spatial distribution of pollutants [19]. Additionally, the scavenging coefficient $\Lambda$ can seem complicated to an everyday reader, and it does not explain directly the scale of the process, since "the man in the street" could have problems interpreting the results of $\Lambda$ reported here. For convenient presentation, the effectiveness of PM10 scavenging by precipitation can also be presented as a simple relationship of percentage change $(\Delta C)$ in the dust mass concentrations before and after episodes of rain. That percentage change is known as "removal coefficient" [20].

The effectiveness of wet deposition in the scavenging of particulate matter from the troposphere has been the subject of reports in a large number of research works $[2,9,16$, 21-29]. These processes are recognized both on a complex scale (including details of the effectiveness of particulate matter scavenging when accompanying particular types of precipitation) and on a detailed scale (when the effectiveness of specific types of particles is investigated with regard to the type of precipitation which carries them). Evidently, many results pertain only to specific circumstances; nevertheless, the local emission of pollution and the structure of rain clouds play a principal role in determining the characteristics of wet deposition [7]. What is noteworthy is that the variations in the concentration of aerosols in the troposphere following precipitation can also occur in areas both in the vicinity of, and remote from pollution sources as a result of the effect of transport with horizontal air masses [16]. With the exception of a few papers [9, 25, 29], authors do not report results of the scavenging of aerosols, which are standard indicators of air quality in a given area.

The distribution of aerosol in the air in terms of particle size and concentration depends not only on the meteorological processes and mechanisms accompanying scavenging from the atmosphere but to a greater degree on the type and intensity of emission from anthropogenic and natural sources [30]. So far, simultaneous and long-term observations in locations with significant diversification of emission sources have not been performed. It is suspected that the value of the PM10 removal coefficient $(\Delta C)$ can be significantly differ in areas with different emission characteristics. The cause may be the scale of emission, the different contribution of individual fractions in PM10 and the chemical properties of pollutants introduced.

The principal objective in this project was to conduct a comparative analysis of scavenging of PM10 with the wet deposition depending on aerosanitary conditions defined by the type and intensity of precipitation. The analysis, which was supported by a considerable amount of data from measurements, was aimed at verifying hypothesis stating that: there are no differences in the effectiveness of the scavenging of PM10 relative to the place of its occurrence (in urban-rural environment relation). 


\section{Materials and methods}

The study, whose results are reported here, was conducted simultaneously in urban (P1) and rural areas (P2) over the period of successive 7 years (2007-2013). The registration of meteorological parameters and concentration of PM10 in the urban area was realized in the provincial city of Opole (Poland, 50 41'13'N; 17 56 '43'E, 122,000 inhabitants). The measurement point P1 was situated in the north-east part of the town, in the vicinity of low residential housing and commercial development and close to a major road into the town with moderate traffic. The meteorological data representative of a non-urban area and concentration of PM10 was measured in an undeveloped area, i.e. in the vicinity of a village (Kotorz Maly, Poland, 5043'37'N; 1803'22'E; 1,025 inhabitants). The measurement point P2 was located on an open, yet shielded meadow area protected by the surrounding wood $-9 \mathrm{~km}$ north-east from point P1 and $2 \mathrm{~km}$ from the nearest compact rural building development. The area of investigation is presented at Figure 1.

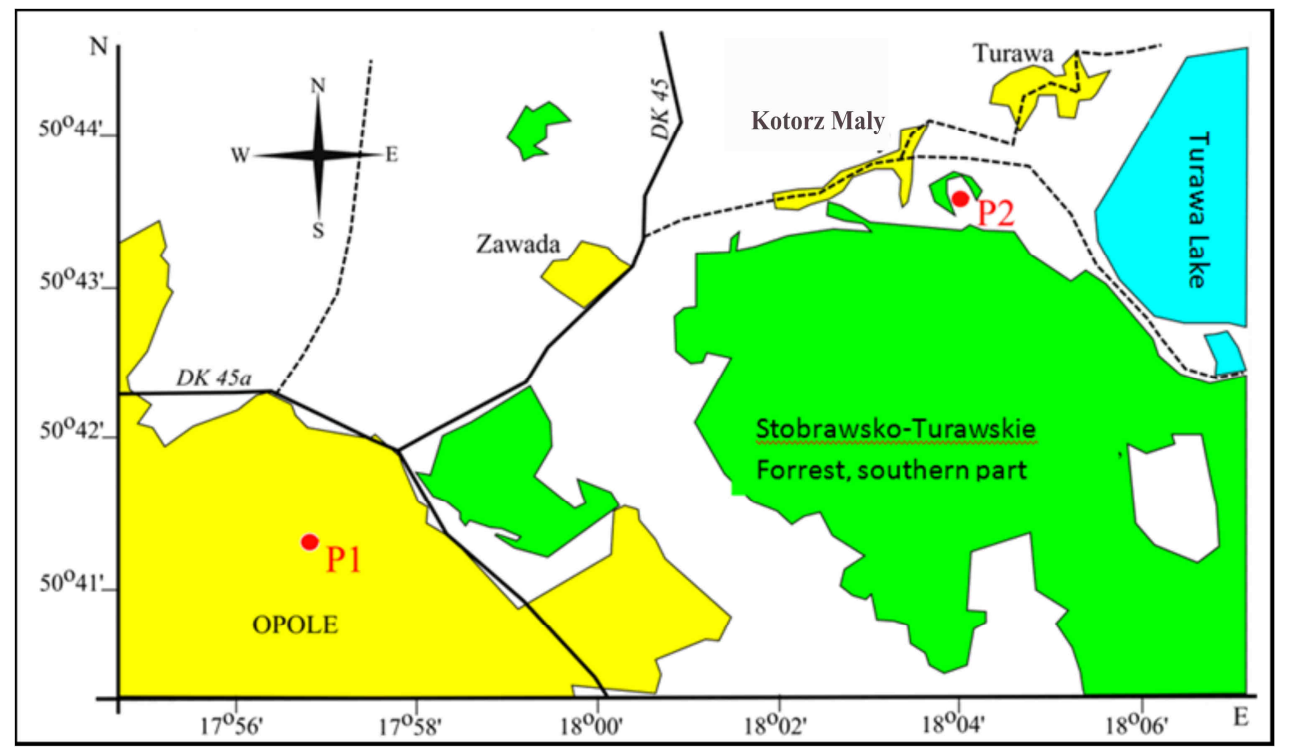

Fig. 1. Localization of observation points; P1 - urban and P2 - rural

The 5-year assessment of air quality published by Opole Voivodeship Inspectorate for Environmental Protection (OVIEP), which involves the analysis of air pollution with particulate matter (PM10 and PM2.5), indicated that Opole is classified in class $3 b^{2}$ with regard to the quality criteria for the protection of human health [31]. This urban area is characterized by considerably higher mean annual values of concentration of PM10 compared to the distant and partly isolated rural area. For instance, according to OVIEP data [32], the mean annual concentration of PM10 in Opole was equal to $33.3 \mu \mathrm{g} \cdot \mathrm{m}^{-3}$ in

\footnotetext{
${ }^{2}$ Class $3 b$ - area in which the level of concentration of pollution is higher than the upper assessment threshold established for this type of substance in the air; this level invokes a need to conduct intensive and continuous registration of data in measuring stations in the areas exceeding the admissible levels.
} 
2013 , which is $83.2 \%$ of the admissible level. This result is confirmed by the mean annual concentration of PM10 measured in the present study $\left(36.4 \mu \mathrm{g} \cdot \mathrm{m}^{-3}\right)$, which was recorded at the observation point P1. Concurrently, the mean annual concentration of PM10 measured in the rural area (P2) was $40 \%$ lower.

The measurement campaign involved the observation of the PM10 concentration resulting from the occurrence of two types of precipitation with different intensity: solid and liquid (frontal and convective ones). In order to further verify the results of the research, the analysis involved only the cases of wet deposition occurring simultaneously at the two measurement points. The detailed analysis involved episodes of hydrometeors which occurred simultaneously and were characterized by the nearly identical intensity of precipitation $R\left[\mathrm{~mm} \cdot \mathrm{h}^{-1}\right.$ ]. The time interval of the particular aspirations was constant and equal to 30 minutes. Both short-term $(0.5 \mathrm{~h})$ and long-term $(>2 \mathrm{~h})$ instances of precipitation were considered in the analysis.

\section{Meteorological data and PM10 sampling procedure}

To determine the meteorological conditions, portable weather stations (Lacross Technology $^{\circledR}$ and DAVIS ${ }^{\circledR}$ ) were used, which are widely used for registration of weather conditions in field measurements [33]. These weather stations were installed 10 (at P1) and 12 (at P2) meters from the PM aspirators. At both measurement points, the sensors, which determined relative humidity $(R H)$, temperature $(T)$, atmospheric pressure $(P)$, wind speed $(W s)$ and rainfall $(R)$, were installed at a height of $2 \mathrm{~m}$ above the ground. The standard measurement uncertainty was equal to: $R H 0.5 \%, T 0.5^{\circ} \mathrm{C}, P 0.06 \mathrm{hPa}, W s 0.06 \mathrm{~m} \mathrm{~s}^{-1}$, respectively.

The procedure by which the measurement of the mass concentration of PM10 was performed was in conformity with the European standard [34]. The aspiration of the PM10 in the air was carried out by a MicroPNS HVS16 (UMWELTTECHNIK MCZ GmbH ${ }^{\circledR}$ ) sequential dust samplers. Like the sensors in the weather stations, the aspiration headers were installed $2 \mathrm{~m}$ above ground level. The flow rate was $68 \mathrm{~m}^{3} \mathrm{~h}^{-1}$. The PM separators applied Whatman GF/A fibreglass air filters with a diameter of $150 \mathrm{~mm}$. The expanded concentration measurement uncertainty (U) did not exceed $3.9 \%$. The time interval guaranteed the PM collection to a degree that was sufficient to determine the mass of the captured particulate matter, even in conditions when its concentration in the air was low. The initial testing $(n=25$, time interval of registration - 10 seconds, time of a single registration - 1800 seconds) using a DustTrak 8520 Aerosol Monitor - TSI ${ }^{\circledR}$, was conducted in variable weather conditions; however, with the exception of rain, it did not yield considerable differences in the results of PM10 concentration over 10 and 1800 seconds in the investigated area.

\section{Procedure for determining the removal coefficient $\Delta C$}

The removal coefficient of the particulate matter was determined with the relation (1):

$$
\Delta C=\frac{C_{t}-C_{0}}{C_{0}} \cdot 100 \%
$$

where: $C_{0}$ - mass concentration of PM10 before precipitation episodes, $C_{t}-$ mass concentration of PM10 after precipitation episodes.

The proposed solution has a primarily practical character and constitutes an attempt to offer a way of approaching the effect of scavenging of particulate matter suspended in the 
ground-level zone. As the scavenging coefficient $\Lambda$, the removal coefficient $\Delta C$ is relative to the aerodynamic diameter of the PM; however, due to the applied measurement methodology, the entire fraction of PM with the diameter below $10 \mu \mathrm{m}$ was identified. Statistical analysis of the results of meteorological parameters and variability of the mass concentration of PM10 for verification of research hypothesis was undertaken by means of the STATISTICA $12^{\circledR}$ program.

\section{Results and discussion}

\section{Characteristics of meteorological parameters}

Table 1 contains a summary of data regarding meteorological parameters registered during the experiment. The data involves only the records for those days when solid or liquid precipitation occurred at both observation points. None of the recorded cases were found to correspond to a normal distribution of data, as indicated by the Shapiro-Wilk test. At the same time, intensity of precipitation, wind force and direction are similar. This results mostly from the location of the two observation points in the vicinity of each other and the similar origin of the processes of wet deposition. For the case of convective light precipitation $\left(R<0.5 \mathrm{~mm} \cdot \mathrm{h}^{-1}\right)$, the mean air temperature in the urban area was around $1.5^{\circ} \mathrm{C}$ higher than in the rural surrounding and its value was two times higher than the temperature recorded for large-scale precipitation in both areas.

Table 1

Meteorological parameters characterizing the conditions during the observations at both places

\begin{tabular}{|c|c|c|c|c|c|c|c|c|}
\hline $\begin{array}{c}\text { Place of } \\
\text { observation }\end{array}$ & $\begin{array}{c}\text { Statistical } \\
\text { description }\end{array}$ & $\begin{array}{c}T \\
{\left[{ }^{\circ} \mathbf{C}\right]}\end{array}$ & $\begin{array}{l}\mathrm{RH} \\
{[\%]}\end{array}$ & $\begin{array}{c}R \\
{\left[\mathrm{~mm} \cdot \mathbf{h}^{-1}\right]}\end{array}$ & $\begin{array}{c}P \\
{[\mathrm{hPa}]}\end{array}$ & $\begin{array}{c}W_{s} \\
{\left[\mathrm{~m} \cdot \mathrm{s}^{-1}\right]}\end{array}$ & $\begin{array}{l}\text { PM10 } C_{0} \\
{\left[\mu \mathrm{g} \cdot \mathrm{m}^{-3}\right]}\end{array}$ & $\begin{array}{l}\mathrm{PM10} C_{t} \\
{\left[\mu \mathrm{g} \cdot \mathrm{m}^{-3}\right]}\end{array}$ \\
\hline \multicolumn{9}{|c|}{$(C R)$ - convective precipitation (without storms) } \\
\hline \multirow{6}{*}{$\mathrm{P} 1$} & Avg & 19.0 & 84.0 & 0.70 & 991 & 2.82 & 22.3 & 20.0 \\
\hline & Med & 19.0 & 87.0 & 0.45 & 990 & 2.40 & 22.0 & 20.0 \\
\hline & SD & 3.80 & 10.0 & 0.72 & 7.50 & 4.18 & 11.0 & 10.4 \\
\hline & Max & 30.5 & 95.0 & 4.00 & 1007 & 22.9 & 62.0 & 59.1 \\
\hline & Min & 11.6 & 50.0 & 0.20 & 974 & 0.00 & 16.0 & 13.0 \\
\hline & $\mathrm{C}_{\mathrm{V}}[\%]$ & 20.0 & 11.9 & 103 & 0.76 & 148 & 49.3 & 52.0 \\
\hline \multirow{6}{*}{$\mathrm{P} 2$} & Avg & 19.0 & 81.0 & 1.06 & 990 & 3.13 & 16.9 & 13.9 \\
\hline & Med & 18.9 & 84.0 & 0.75 & 990 & 2.80 & 16.2 & 13.6 \\
\hline & SD & 3.64 & 12.0 & 0.91 & 5.09 & 2.91 & 7.79 & 6.61 \\
\hline & Max & 28.9 & 94.0 & 7.40 & 1009 & 26.3 & 42.0 & 38.0 \\
\hline & Min & 8.5 & 62.0 & 0.20 & 975 & 0.00 & 13.4 & 7.10 \\
\hline & $\mathrm{C}_{\mathrm{V}}[\%]$ & 19.2 & 14.8 & 85.8 & 0.51 & 93.0 & 46.0 & 47.6 \\
\hline \multicolumn{9}{|c|}{$(F R)$ - frontal (large-scale) liquid precipitation } \\
\hline \multirow{6}{*}{ P1 } & Avg & 11.1 & 88.0 & 0.93 & 996 & 5.84 & 22.7 & 20.6 \\
\hline & Med & 11.1 & 90.0 & 0.60 & 995 & 3.80 & 18.0 & 16.0 \\
\hline & SD & 4.30 & 0.07 & 1.08 & 9.24 & 6.06 & 18.5 & 18.1 \\
\hline & Max & 23.5 & 99.0 & 11.2 & 1019 & 28.7 & 222 & 186 \\
\hline & Min & 1.90 & 59.0 & 0.20 & 985 & 0.00 & 13.0 & 7.00 \\
\hline & $\mathrm{C}_{\mathrm{V}}[\%]$ & 38.7 & 0.08 & 116 & 0.93 & 103.8 & 81.8 & 87.9 \\
\hline \multirow{6}{*}{$\mathrm{P} 2$} & Avg & 9.25 & 88.0 & 0.88 & 997 & 4.77 & 16.4 & 14.5 \\
\hline & Med & 9.10 & 90.0 & 0.50 & 996 & 2.60 & 16.0 & 14.0 \\
\hline & SD & 4.18 & 0.08 & 0.99 & 8.85 & 5.97 & 8.10 & 7.43 \\
\hline & Max & 27.2 & 99.0 & 13.0 & 1017 & 58.8 & 59.0 & 49.0 \\
\hline & Min & 0.00 & 46.0 & 0.20 & 986 & 0.00 & 12.0 & 10.0 \\
\hline & $\mathrm{C}_{\mathrm{V}}[\%]$ & 45.1 & 0.09 & 112 & 0.88 & 125 & 49.5 & 51.4 \\
\hline
\end{tabular}




\begin{tabular}{|c|c|c|c|c|c|c|c|c|}
\hline $\begin{array}{c}\text { Place of } \\
\text { observation }\end{array}$ & $\begin{array}{r}\begin{array}{c}\text { Statistical } \\
\text { description }\end{array} \\
\end{array}$ & $\begin{array}{c}T \\
{\left[{ }^{\circ} \mathbf{C}\right]} \\
\end{array}$ & $\begin{array}{l}\mathrm{RH} \\
{[\%]}\end{array}$ & $\begin{array}{c}R \\
{\left[\mathbf{m m} \cdot \mathbf{h}^{-1}\right]}\end{array}$ & $\begin{array}{c}P \\
{[\mathrm{hPa}]}\end{array}$ & $\begin{array}{c}W_{s} \\
{\left[\mathrm{~m}^{\prime} \cdot \mathrm{s}^{-1}\right]}\end{array}$ & $\begin{array}{l}\text { PM10 } C_{0} \\
{\left[\mu \mathrm{g} \cdot \mathrm{m}^{-3}\right]}\end{array}$ & $\begin{array}{l}\text { PM10 } C_{t} \\
{\left[\mu \mathrm{g} \cdot \mathrm{m}^{-3}\right]}\end{array}$ \\
\hline \multicolumn{9}{|c|}{$(F S)$ - frontal (large-scale) snow precipitation } \\
\hline \multirow{6}{*}{ P1 } & Avg & -0.57 & 87.0 & 0.55 & 992 & 3.56 & 40.8 & 35.7 \\
\hline & Med & -1.10 & 88.0 & 0.40 & 992 & 2.90 & 25.0 & 24.0 \\
\hline & SD & 1.54 & 0.06 & 0.37 & 9.77 & 3.68 & 38.2 & 33.1 \\
\hline & $\operatorname{Max}$ & 3.20 & 95.0 & 3.00 & 1011 & 18.7 & 203 & 162 \\
\hline & Min & -4.90 & 69.0 & 0.20 & 979 & 0.00 & 20.0 & 12.5 \\
\hline & $\mathrm{C}_{\mathrm{V}}[\%]$ & 270 & 0.06 & 67.9 & 0.98 & 103 & 93.5 & 92.7 \\
\hline \multirow{6}{*}{ P2 } & Avg & -1.14 & 87.0 & 0.55 & 993 & 4.16 & 21.8 & 18.6 \\
\hline & Med & -1.40 & 88.0 & 0.40 & 992 & 3.45 & 21.0 & 18.0 \\
\hline & SD & 2.63 & 0.06 & 0.56 & 9.65 & 4.03 & 11.0 & 9.18 \\
\hline & Max & 4.40 & 95.0 & 7.50 & 1012 & 19.6 & 54.0 & 46.0 \\
\hline & Min & -10.4 & 56.0 & 0.20 & 979 & 0.00 & 9.50 & 4.70 \\
\hline & $\mathrm{C}_{\mathrm{V}}[\%]$ & 230 & 0.07 & 101 & 0.97 & 96.8 & 50.3 & 49.3 \\
\hline
\end{tabular}

The registered differences stem from the fact that convective light precipitation was principally limited to the summer season, while large-scale precipitation occurred all year round. The lowest temperatures accompanied occurrences of snowfall, while the temperature intervals corresponding to the urban-rural area distinction did not exceed $5 \%$. For the case of liquid precipitation, for both the urban and the rural area, predominantly small movement of horizontal air masses was noted (in around $50 \%$ of all cases). During large-scale precipitation, a similar number of precipitation instances accompanied windless conditions (around 18\% during observations lasting $0.5 \mathrm{~h}$ and $12 \%$ during occurrences of continuous rainfall). The wind conditions recorded during the episodes of snowfall in both locations were nearly constant (around 32\% of mild winds and 16\% for windless conditions). The humidity level accompanying the occurrence of hydrometeors remained at a constant level for all observations, and it was close to $81 \%$ for convective light rains, $88 \%$ for frontal and $86 \%$ for continuous rain.

A review of literature data indicates that the intensity of precipitation $R$ forms the key parameter in determining the level of particles scavenging from the troposphere. Analysis of the distribution of this parameter for the specific locations and types of precipitation indicates that the dominant type is wet deposition with a low intensity. For the case of short-term observations, precipitation with intensity in the range $<1 \mathrm{~mm} \cdot \mathrm{h}^{-1}$ was noted in about 62,83 and $92 \%$ cases of frontal, convective and snow precipitation types, respectively. Higher variability was noted for long-term precipitation. Snowfall with intensity $<1 \mathrm{~mm} \cdot \mathrm{h}^{-1}$ was registered in $90 \%$ of cases of urban observations and in $97 \%$ of cases in the rural environment. A higher intensity of light rainfall was noted in the urban area $(62 \%)$ than in the rural location $(54 \%)$.

The basic statistical analysis with the application of the Spearman's rank correlation indicated that the relation between the value of $\Delta C$ and $R$ is high and the value of the $r^{2}$ coefficient is high. The calculated determination coefficient offers a considerable degree of explanation for the variability of $\Delta C$, which follows as a consequence of the variability in the intensity of precipitation. On the basis of the analysis of the results gathered for the same values of $R$, it can be note that in regard to the convective short-term precipitation $(0.5 \mathrm{~h})$, the intensity of precipitation in the rural area explains $65 \%$ of cases of the variability of $\Delta C$. For the case of the urban area, this value is $61 \%$. The determination coefficient for the continuous precipitation $(>2 \mathrm{~h}$ ) was found to be at the level of around $45 \%$ for the urban area and $53 \%$ for the rural area. These differences may stem from the 
higher values of the variability coefficient (on average by $35-40 \%$ ) for values of $\Delta C$ derived for the city compared with the same value in the rural area during episodes of precipitation with the same intensity. At the same time, no correlation was found between the value of the removal coefficient and the remaining meteorological parameters registered during the measurements.

\section{Effectiveness of scavenging of PM10 in environments with various aerosanitary characteristics}

The variability of the mass concentration of aerosols during two successive time intervals in the conditions of the actual experiment is related to a variety of conditions, such as turbulence in the boundary layer, chemical processes in the liquid and solid phase, and local emission and transport of pollutants from remote areas [24]. These processes are reflected in both positive and negative values of the removal coefficient measured in the urban and rural areas. During the experiment, incidental instances of positive values of $\Delta C$ were registered for short-term light precipitation, especially for the instances of large-scale rainfall, which confirms the observations made in earlier research [24]. Figures 2 and 3 presented the P1-P2 comparison of removal coefficient values for different types of precipitation and selected range of its intensity.
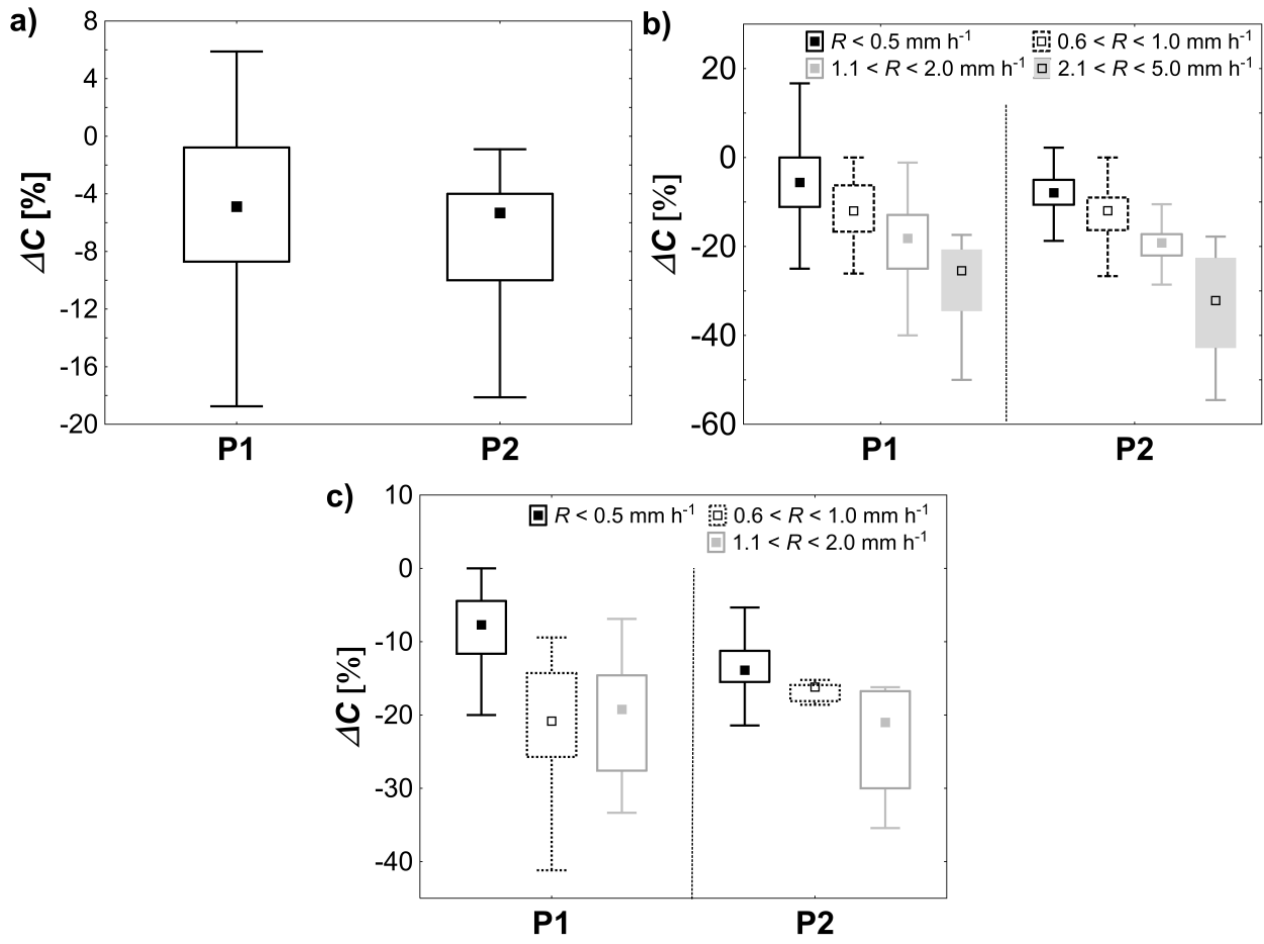

Fig. 2. Urban (P1) and rural (P2) comparison of removal coefficient values for different types of short-term $(0.5 \mathrm{~h})$ precipitation (convective rain $(\mathrm{a})$, frontal rain (b), frontal snow (c). For convective rain data for $R<0.5 \mathrm{~mm} \cdot \mathrm{h}^{-1}$ only) 
The effectiveness of scavenging of tropospheric aerosol is most commonly described in terms of a median derived by means of an experiment. On the basis of the data classified as convective short-term $(0.5 \mathrm{~h})$ precipitation during the entire duration of the experiment, the lack of a considerable difference was noted between the urban (P1) and rural (P2) area, as the medians of $\Delta C$ were equal to -6.12 and $-6.51 \%$, respectively. A similar situation was registered during the analysis of episodes of convective precipitation occurring concurrently and characterized by an identical intensity $R$ (i.e. with $\Delta C$ medians -5.22 and $-5.81 \%$, respectively).

The comparison of the calculated values of median $\Delta C$ for observations of large-scale liquid precipitation, with regard to the urban-rural opposition, also yields similar values for observations limited to the same date of occurrence and light and medium precipitation intensity (i.e. for $R<0.5 \mathrm{~mm} \cdot \mathrm{h}^{-1}$ close to $-6.5 \%$ at $\mathrm{P} 1$ and $\mathrm{P} 2$; for $R=0.6-1.0 \mathrm{~mm} \cdot \mathrm{h}^{-1}$ close to $-12 \%$ and for $R=1.1-2.0 \mathrm{~mm} \cdot \mathrm{h}^{-1}$ close to $-18.5 \%$ ). For high precipitation intensity $\left(R=2.1-5.0 \mathrm{~mm} \cdot \mathrm{h}^{-1}\right)$ the difference between the removal coefficient values for $\mathrm{P} 1$ and $\mathrm{P} 2$ appeared (close to $-27 \%$ for P1 and $-32 \%$ for P2). Also higher levels of divergence were observed during short-term and low-intensity snowfall occurrences, where the medians of the removal coefficient were equal to $-8 \%$ (urban area) and $-13 \%$ (rural area). For the case of long-term precipitation (Fig. 3), the amount of data collected was not sufficient to compare the results for the convective ones.

Long-term frontal precipitation and snowfall were characterized by different values of the median of removal coefficient depending on the measurement location. For the case of long-term liquid precipitation, the medians of $\Delta C$ were similar for the urban and rural area only for rain intensity greater than $1.1 \mathrm{~mm} \cdot \mathrm{h}^{-1}$.
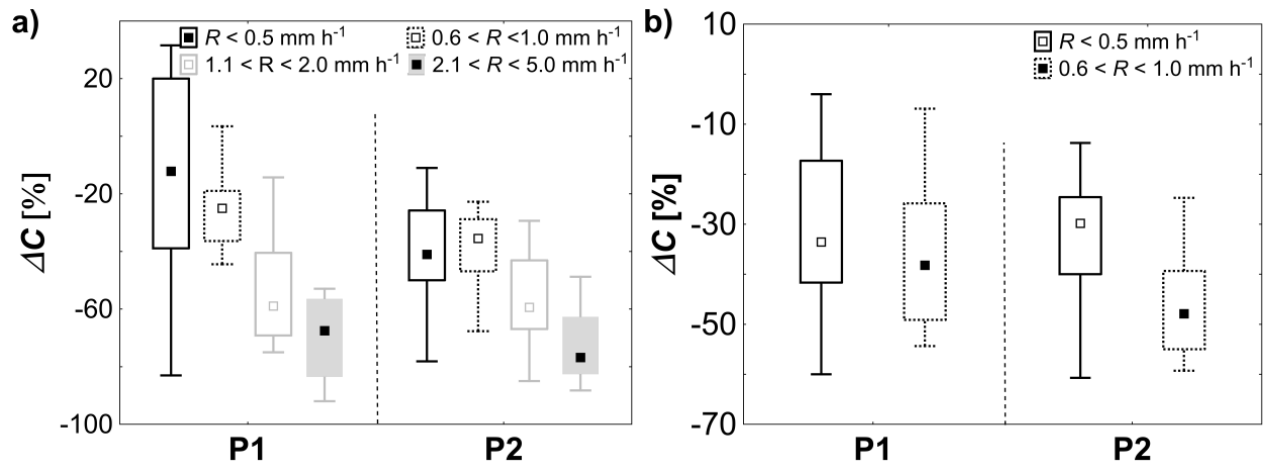

Fig. 3. Urban (P1) and rural (P2) comparison of removal coefficient values for different types of long-term (> $2 \mathrm{~h}$ ) precipitation: a) frontal rain, b) frontal snow

Table 2 summarizes the results of the Mann-Whitney test, whose aim was to verify the hypothesis stating that the effectiveness of scavenging of PM10 is identical regardless of the place of occurrence of the process of wet deposition. The results ( $p$-value) presented in the first two rows of the table refer to the data discussed in the earlier paragraphs, which is expressed by specific values of $\Delta C$. Only in the case of convective and continuous largescale precipitation (for identical observation time and intensity $R$ ), the results of the test unambiguously confirm the fact that the scavenging at the two different environments is 
virtually the same. The value of the probability confirmed by the large number of analyzed incidences of snowfall and short-term frontal rainfall excludes the proportionality of the effectiveness of scavenging in the urban and rural area, despite the similar values of the median of removal coefficient. Detailed analysis of the occurrences of light precipitation (for the same observation time, $R \leq 0.5 \mathrm{~mm} \cdot \mathrm{h}^{-1}$ ) indicates that the location of the scavenging occurrence does not play a role either in the case of convective precipitation or for the case of convective light rains and long-term solid and liquid precipitation of frontal character. This fact can be explained by the thermal conditions. For the case of convective precipitation which accompanies a relatively high ambient temperature, the effect of particulate matter emission from thermal energy sources is particularly discernible (especially from local sources of thermal energy). On the other hand, the registered snowfall and frontal rainfalls coincided with the cold and moderate season, which is associated with intensive exploitation of anthropogenic emission sources and permanent introduction of pollutant loads. In these conditions, short-term precipitation is incapable of purging pollutants from the atmosphere with similar effectiveness in the examined areas. During the occurrence of intermediate and high intensity precipitation $\left(R>0.5 \mathrm{~mm} \cdot \mathrm{h}^{-1}\right)$, the urban environment, which is enriched with pollutants continuously, is characterized by a similar effect of wet deposition to that in the rural area. Similar conclusions regarding scavenging of particulate matter with diameters measured in microns is presented in the work by [35]. Much more effective removal of the examined dust after the average snowfall has been observed in the city area. The result is confirmed by 17 independent observations, which excludes randomness.

$p$-value for $\Delta C_{P 1}-\Delta C_{P 2}$ relation. In the bracket No. of observation registered.

Bold values indicate realization of Mann-Whitney test conditions (for significance level $\alpha=0.05$ )

\begin{tabular}{|c|c|c|c|c|c|}
\hline \multirow{2}{*}{ Conditions of observation } & \multicolumn{5}{|c|}{ Type and duration of precipitation } \\
\cline { 2 - 6 } & $\boldsymbol{C R}(\mathbf{0 . 5} \mathbf{h})$ & $\boldsymbol{F S}(\mathbf{0 . 5} \mathbf{h})$ & $\boldsymbol{F S}(>\mathbf{2} \mathbf{h})$ & $\boldsymbol{F R}(\mathbf{0 . 5} \mathbf{h})$ & $\boldsymbol{F R}(>\mathbf{2} \mathbf{~ h})$ \\
\hline$t=$ const, $R=$ const & $\mathbf{0 . 3 2}(20)$ & $<0.001(94)$ & $\mathbf{0 . 2 1}(22)$ & $0.035(245)$ & $\mathbf{0 . 0 7}(45)$ \\
\hline$t=$ const, $R \leq 0.5 \mathrm{~mm} \cdot \mathrm{h}^{-1}$ & $\mathbf{0 . 2 1}(18)$ & $<0.001(71)$ & $\mathbf{0 . 5 0}(14)$ & $0.002(114)$ & $\mathbf{0 . 0 9}(10)$ \\
\hline$t=$ const, $0.6 \leq R \leq 1.0 \mathrm{~mm} \cdot \mathrm{h}^{-1}$ & no data & $<0.001(17)$ & $\mathbf{0 . 2 4}(8)$ & $\mathbf{0 . 4 0}(59)$ & $0.03(17)$ \\
\hline$t=$ const, $1.1 \leq R \leq 2.0 \mathrm{~mm} \cdot \mathrm{h}^{-1}$ & no data & $\mathbf{0 . 7 5}(6)$ & no data & $\mathbf{0 . 4 2}(43)$ & $\mathbf{0 . 9 9}(14)$ \\
\hline$t=$ const, $2.1 \leq R \leq 5.0 \mathrm{~mm} \cdot \mathrm{h}^{-1}$ & no data & no data & no data & $\mathbf{0 . 3 3}(28)$ & $\mathbf{0 . 8 8}(4)$ \\
\hline $\begin{array}{c}\text { Continuous precipitation, } t=2 \mathrm{~h}, \\
R=\text { const }\end{array}$ & no data & no data & $0.005(8)$ & no data & $\mathbf{0 . 2 5}(8)$ \\
\hline $\begin{array}{c}\text { Continuous precipitation, } t=3 \mathrm{~h}, \\
R=\text { const }\end{array}$ & no data & no data & $\mathbf{0 . 8 1}(6)$ & no data & $\mathbf{0 . 2 7}(10)$ \\
\hline $\begin{array}{c}\text { Continuous precipitation, } t=4 \mathrm{~h}, \\
R=\text { const }\end{array}$ & no data & no data & no data & no data & $\mathbf{0 . 5 3}(9)$ \\
\hline $\begin{array}{c}\text { Continuous precipitation, } 5<t<10 \mathrm{~h}, \\
R=\text { const }\end{array}$ & no data & no data & no data & no data & $\mathbf{0 . 6 4}(16)$ \\
\hline
\end{tabular}

The result of a much lower value $\Delta C$ in the city is difficult to explain. A possible explanation for the discrepancy may be the periodic strengthening of the effect of particles removal by occurring the downdraught over the city area. This effect is associated with changes in the boundary layer caused by the increased emission of anthropogenic impurities [36, 37]. On the other hand, perhaps the effect of "the Urban Heat Island" increases the efficiency of dust capture by snowflakes. Snowflakes when exposed to higher ambient temperatures, are better hydrated and increase their surface contact with solid 
particles. In the context of the adopted methodology, an equally important parameter determining the effectiveness of air purification from particulate matter may be the initial PM10 mass concentration. According to the authors [38] the best dust removal efficiency during precipitation occurs at the initial stage of the process. At the same time, it has been proven that "large" particles are washed out more efficiently than smaller ones [38]. That large particles determine the value of PM10 mass concentration. Another important factor influencing the change in particle concentration is the properties of the dust removed. Dust from different sources differs in chemical and granulometric composition, as confirmed by field observations [39]. By accepting the constant value of the pollutant load, it can be stated that anthropogenic emissions (fuel combustion) generate more submicron particles than dust from natural sources. Hence, the properties of the dust can have a significant effect on the PM10 mass concentration changes in both locations.

A complement to this report can be offered by the results of analysis of incidences of continuous precipitation with constant intensity $R$ according to its duration. The results of the test, under the assumption of a constant scale of particulate matter transport from remote areas, clearly indicate that a longer duration of the continuous process of wet deposition limits the divergences in the value of $\Delta C$ derived for two environments with various levels of local emission. One can, however, note that the removal coefficient assumes lower values in the rural area under the assumption of identical intensity and duration of precipitation.

Comparative analysis of the two different environments in terms of the volume and character of emission indicates that low intensity precipitation leads to statistically relevant differences in the value of the $\Delta C$. Table 3 presents the results of the Mann-Whitney test with a comparison of the values of removal coefficient for distinct locations of light precipitation depending on the initial concentration of pollutants measured directly before the episodes of wet deposition process. For a standard drizzle with low intensity, there are no statistically relevant differences. For the case of the occurrence of continuous precipitation, the removal coefficient assumes various values in the examined locations. With the exception of convective precipitation, for the remaining types of hydrometeors with the intensity of $0.4 \mathrm{~mm} \cdot \mathrm{h}^{-1}$, statistically relevant differences in the value of $\Delta C$ are registered, regardless of the initial mass concentration of PM10.

Table 3

A comparison of removal coefficient according to urban-rural area distinction. The results of probability test ( $p$-value) for different types of precipitation and different range of "before rain" PM10 concentration. Bold values showed realization of conditions of Mann-Whitney test (critical $p$-value: 0.05)

\begin{tabular}{|c|c|c|c|}
\hline Precipitation type and intensity & $\boldsymbol{C}_{\mathbf{0}}<\mathbf{1 5} \boldsymbol{\mu g} \cdot \mathbf{m}^{-\mathbf{3}}$ & $\boldsymbol{C}_{\mathbf{0}} \mathbf{1 5}<\mathbf{3 ~ 0} \boldsymbol{\mu g} \cdot \mathbf{m}^{-\mathbf{3}}$ & $\boldsymbol{C}_{\mathbf{0}}>\mathbf{3 0} \boldsymbol{\mu g} \cdot \mathbf{m}^{-\mathbf{3}}$ \\
\hline convective,$R=0.2 \mathrm{~mm} \cdot \mathrm{h}^{-1}$ & $\mathbf{0 . 6 5}$ & $\mathbf{0 . 4 4}$ & $\mathbf{0 . 1 7}$ \\
\hline convective $R=0.4 \mathrm{~mm} \cdot \mathrm{h}^{-1}$ & $\mathbf{0 . 0 9}$ & $\mathbf{0 . 0 8}$ & 0.06 \\
\hline snow $R=0.2 \mathrm{~mm} \cdot \mathrm{h}^{-1}$ & 0.04 & 0.01 & 0.03 \\
\hline snow $R=0.4 \mathrm{~mm} \cdot \mathrm{h}^{-1}$ & $<0.01$ & 0.01 & 0.02 \\
\hline frontal $R=0.2 \mathrm{~mm} \cdot \mathrm{h}^{-1}$ & $\mathbf{0 . 3 5}$ & $\mathbf{0 . 2 4}$ & $\mathbf{0 . 0 7}$ \\
\hline frontal $R=0.4 \mathrm{~mm} \cdot \mathrm{h}^{-1}$ & 0.02 & 0.01 & 0.03 \\
\hline
\end{tabular}

Although it is difficult to identify the exact reasons, the results of this study confirm the early statement that for convective precipitation accompanied by high air temperatures can be found a limitation of the intensity of local emission from anthropogenic sources, which causes the registration of similar values of $\Delta C$ in both the examined locations. On the 
other hand, the activity of the local anthropogenic sources during episodes of short-term snowfalls and frontal rains results in considerable differences in the effectiveness of scavenging between the urban and rural area. Therefore, field research seems to confirm the observations made in a work by Shukla et al. [26], in which the authors observed that the degree of scavenging is related to the volume of the local emission despite the primary focus of work on theoretical research. A similar conclusion was made on the basis of a study into concentrations of particulate matter in various locations (urban and rural area, communication infrastructure) in Spain [40].
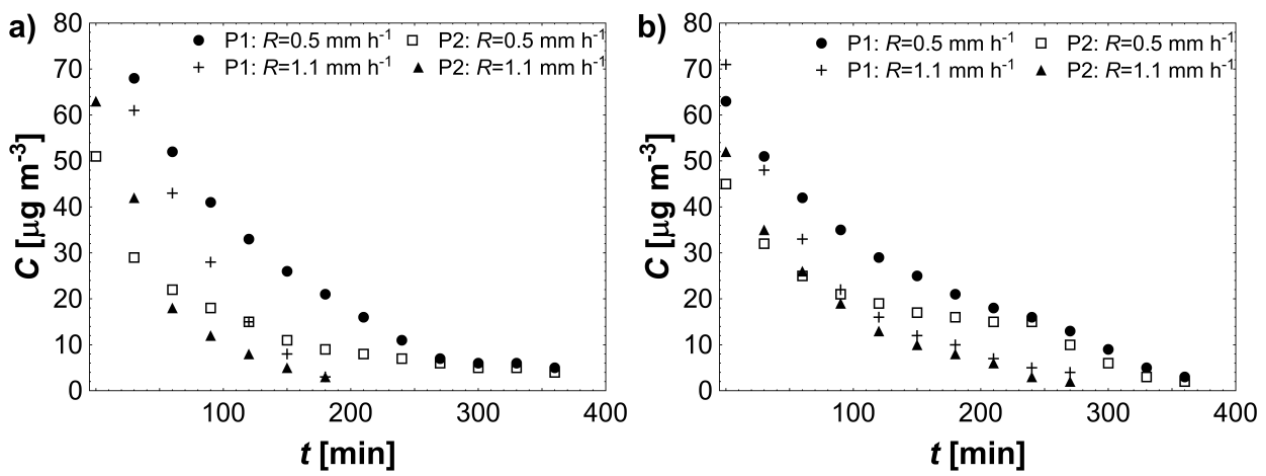

Fig. 4. Change of PM10 mass concentrations at P1 and P2 sites during simultaneous occurrence of long-term solid and liquid large-scale (frontal) precipitation; a) frontal snow, b) frontal rain

The available results of field research indicate that removing of particulate matter from the atmosphere is related not only to the intensity but also to the duration of the precipitation. By considering the results collected during the episodes of long-term continuous precipitation, one can note that the value of the $\Delta C$ decreases slowly over time (Fig. 4). This fact is associated with the depletion of solid particles in the ground-level zone. On the basis of the analysis of the concurrent occurrences of continuous precipitation, it was observed that the variation of PM10 mass concentration is greater in the less polluted rural area. For instance, as a result of liquid precipitation with an intensity of $1.0 \mathrm{~mm} \cdot \mathrm{h}^{-1}$ in the rural area, the value of $C\left[\mu \mathrm{g} \cdot \mathrm{m}^{-3}\right]$ assumes $60 \%$ of its initial value after one hour, while it is around $0 \%$ after 3 hours (in comparison to registration of the variation in concentration in the first 30 minutes). By analogy, for the urban area, these values are equal to $0 \%$ and $2 \%$, respectively. Concurrently, it was observed that, regardless of the location, during liquid precipitation with constant intensity (i.e. $0.6,1.0 \mathrm{~mm} \cdot \mathrm{h}^{-1}$ ), after 4 hours of the process, the values of the mass concentration do not indicate statistically relevant differences, while after 6 hours the values are close to $0 \mu \mathrm{g} \cdot \mathrm{m}^{-3}$ which indicates that the particulate matter has been removed from the ambient air completely. For the case of snow, scavenging, in particular in the rural area, tends to be even more intense. A value of $60 \%$ of the initial value of mass concentration is observed after 60 minutes in relation to the initial value, for the intensity of precipitation $0.6 \mathrm{~mm} \cdot \mathrm{h}^{-1}$. For the urban area, snowfall with the same intensity lasting for an hour results in the decrease of $C$ by about $33 \%$. Concurrently, snowfall with a constant intensity of $0.6 \mathrm{~mm} \cdot \mathrm{h}^{-1}$ results in almost complete removal of PM10, both in the urban and the rural environment after 3.5 hours. 
The initial statistical analysis of the results indicates that the velocity of horizontal air masses does not affect the value of the removal coefficient. Nevertheless, on the basis of the considerable bulk of raw data ( $n=72$ for snow and $n=157$ for frontal rain) regarding precipitation with a constant intensity $0.4 \mathrm{~mm} \mathrm{~h}^{-1}$, a verification was undertaken with the aim of checking whether the direction of the horizontal air masses has an effect on the value of $\Delta C$. Table 4 presents the results of the Mann-Whitney test, and illustrates the comparison of the calculated values of $\Delta C$ for each of the locations depending on the direction of the incoming wind (or in the condition of windless weather). The results indicate clearly that for precipitation of various types and constant intensity, the direction of the incoming air masses does not have any effect on the value of the removal coefficient. However, during constant rainfall, one can note that the value of probability is close to a critical value for the case of $\Delta C$ derived during the movement of air masses from the $\mathrm{W}$ and $\mathrm{E}$ direction. This could suggest that the emission from the compact rural development located at a distance of $2 \mathrm{~km}$ west of the measurement point could affect the air quality outside its boundaries (the median of $\Delta C$ is lower during the wind direction from the west than from the east).

Table 4

The Mann-Whitney test results (critical $p$-value: 0.05 ). Comparison of removal coefficient for $R=0.4 \mathrm{~mm} \cdot \mathrm{h}^{-1}$ due to wind direction. Text in italics indicates data for $p$-value in the rural area

\begin{tabular}{|c|c|c|c|c|c|}
\hline \multicolumn{6}{|c|}{ Snow washout } \\
\hline urban & & & & & rural \\
\hline \multicolumn{6}{|l|}{$R=0.4$} \\
\hline & $\mathrm{N}$ & $\mathrm{E}$ & $S$ & $\mathrm{~W}$ & no wind \\
\hline $\mathrm{N}$ & & 0.74 & 0.52 & 0.46 & 0.63 \\
\hline$E$ & 0.18 & & 0.22 & 0.64 & 0.64 \\
\hline$S$ & 0.19 & 0.15 & & 0.18 & 0.18 \\
\hline $\mathrm{W}$ & 0.79 & 0.06 & 1.00 & & 0.93 \\
\hline no wind & 0.60 & 0.16 & 1.00 & 0.68 & \\
\hline \multicolumn{6}{|c|}{ Frontal washout } \\
\hline urban & & & & & rural \\
\hline \multicolumn{6}{|l|}{$R=0.4$} \\
\hline & $\mathrm{N}$ & $\mathrm{E}$ & $\mathrm{S}$ & $\mathrm{W}$ & no wind \\
\hline $\mathrm{N}$ & & 0.89 & 0.94 & 0.75 & 0.89 \\
\hline $\mathrm{E}$ & 0.93 & & 0.90 & 0.29 & 0.89 \\
\hline $\mathrm{S}$ & 1.00 & 1.00 & & 0.99 & 0.85 \\
\hline $\mathrm{W}$ & 0.82 & 0.26 & 0.84 & & 0.59 \\
\hline no wind & 0.96 & 0.80 & 0.79 & 0.60 & \\
\hline
\end{tabular}

\section{Conclusions}

The comparison for the considered locations indicates that the removal coefficient $\Delta C$, derived for the whole set of data, including the instances of concurrent occurrence of hydrometeors with the same intensity, has a little bit higher values in rural areas. At the same time, for light convective precipitation we can observe more effective scavenging of PM10 caused by snowfall. The results of experiments confirm the influence of the precipitation intensity on the effectiveness of scavenging. The determined values of $\Delta C$ for the specific types of precipitation are in the range from -5 to $-35 \%$, which confirms the statement made by earlier authors regarding short-term precipitation. However, it is evident that fine particulate matter, e.g. with a fraction of $1 \mu \mathrm{m}$, tends to be removed with the rain 
to a lesser degree compared to bigger particles (e.g. 8 or $10 \mu \mathrm{m}$ ). The results of long-term observations also indicate that the values of $\Delta C$ derived by means of actual experiments tend to be nearly an order of magnitude higher than those derived on the basis of theoretical models.

The mass concentration of particulate matter with equivalent particle diameters below $10 \mu \mathrm{m}$ is the parameter which indicates the ambient air quality according to many national legislations. The measurements of the variations of PM10 mass concentration are supplemented by the results of continuous registration of the parameters that characterize the process of wet deposition and form a supplement to the state of knowledge regarding the scavenging of particulate matter from the atmosphere. The results of comparative analysis indicate that the intensity of the local emission, mainly of anthropogenic origin, has a major effect on the effectiveness of the scavenging process. The applied methodology does not enable the assessment of the effect of particles with a strictly defined diameter; however, the large volume of the collected results can be applied in the validation of the dispersion and deposition models.

\section{Acknowledgements}

The author wish to kindly thank the authorities of the Mechanics Department of Opole University of Technology for providing the necessary equipment and financial support, without which it would not have been possible to carry out this research project.

\section{References}

[1] Connan O, Maro D, Hebert D, Roubsard P, Goujon R, Lettelier B et al. Wet and dry deposition of particles associated metals $(\mathrm{Cd}, \mathrm{Pb}, \mathrm{Zn}, \mathrm{Ni}, \mathrm{Hg})$ in a rural wetland site, Marais Vernier, France. Atmos Environ. 2013; 67:394-403. DOI: 10.1016/j.atmosenv.2012.11.029.

[2] Santachiara G, Prodi F, Belosi F. Atmospheric aerosol scavenging processes and the role of thermo- and diffusio-phoretic forces. Atmos Res. 2013;128:46-56. DOI: 10.1016/j.atmosres.2013.03.004.

[3] Ebert P, Kibler M, Mainka A, Terbenken B, Baechmanj K, Frank G et al. A field study of particle scavenging by raindrops of different sizes using monodisperse trace aerozol. Aerosol Sci. 1998; 29:173-186. DOI: 10.1016/S0021-8502(97)00043-8.

[4] Zhao TL, Gong SL, Zhang XY, McKendry IG. Modeled size-segregated wet and dry deposition budgets of soil dust aerosol during ACE-Asia 2001: implications for trans-Pacific transport. J Geophys Res. 2003;108:8665-8673. DOI: 10.1029/2002JD003363.

[5] Andronache C. Diffusion and electric charge contributions to below-cloud wet removal of atmospheric ultra-fine aerosol particles. Aerosol Sci. 2004;35:1467-1482. DOI: 10.1016/j.jaerosci.2004.07.005.

[6] Kim J, Jung CH, Choi BC, Oh SN, Brechtel FJ, Yoon SC, et al. Number size distribution o fatmospheric aerosols during ACE-Asia dust and precipitation events. Atmos Environ. 2007;41:441-485. DOI: 10.1016/j.atmosenv.2007.02.024.

[7] Chate DM, Rao P, Naik M, Momin G, Safai P, Ali K. Scavenging of aerosols and their chemical species by rain. Atmos Environ. 2003;37:2477-2484. DOI: 10.1016/S1352-2310(03)00162-6.

[8] Murakami M, Kimura T, Magono C. Observation of precipitation scavenging for water-soluble particles. J Meteo Soc Japan 1983;61:346-357. DOI: 10.2151/jmsj1965.61.3_346.

[9] Schumann T. Large discrepancies between theoretical and field-determined scavenging coefficients. J Aerosol Sci. 1989;20:1159-1162. DOI: 10.1016/0021-8502(89)90786-6.

[10] Flossmann AI. A 2-D spectral model simulation of the scavenging of gaseous and particulate sulfate by a warm marine cloud. Atmos Res. 1994;32: 233-248. DOI: 10.1016/0169-8095(94)90063-9.

[11] Pruppacher HR, Klett JD. Microphysics of Clouds and Precipitation. Second edition. Norwell, Massachusetts: Kluwer Academic; 1997.

[12] Wang PK, Pruppacher HR. On the efficiency with which aerosol particles of radius less than $1 \mu \mathrm{m}$ are collected by columnar ice crystals. Pure Appl Geophys. 1980;118:1090-1108. DOI: 10.1007/BF01593053. 
[13] Tinsley BA, Rohrbaugh RP, Hei M. Electroscavenging in clouds with broad droplet size distributions and weak electrification. Atmos Res. 2001;59-60:115-135. PII: S0169-8095(01)00112-0.

[14] Bae SY, Jung CH, Kim YP. Relative contributions of individual phoretic effect in the below-cloud scavenging process. Aerosol Sci. 2009;40:621-632. DOI: 10.1016/j.jaerosci.2009.03.003.

[15] Feng J. A size-resolved model for below-cloud scavenging of aerosols by snowfall. J Geophys Res. 2009;114:D8. DOI: 10.1029/2008JD011012.

[16] Chate DM, Murugavel P, Ali K, Tiwari S, Beig G. Below-cloud rain scavenging of atmospheric aerosols for aerosol deposition models. Atmos Res. 2011;99:528-536. DOI: 10.1016/j.atmosres.2010.12.010.

[17] Radke LF, Hobbs PV, Eltgroth MW. Scavenging of aerosol particles by precipitation. J Appl Meteorol. 1980;19:715-722. DOI: 10.1175/1520-0450(1980)019<0715:SOAPBP> 2.0.CO;2

[18] Andronache C, Gronholm T, Laakso L, Phillips V, Venalainen A. Scavenging of ultrafine particles by rainfall at a boreal site: observations and model estimations. Atmos Chem Phys. 2006;6:4739-4754. DOI: 10.5194/acp-6-4739-2006.

[19] Bae SY, Jung CH, Kim YP. Derivation and verification of an aerosol dynamics expression for the below-cloud scavenging process using the moment 41 (2010). J Aerosol Sci. 2010;41:266-280. DOI: 10.1016/j.jaerosci.2009.11.006.

[20] Olszowski T. Changes in PM10 concentration due to large-scale rainfall. Arab J Geosci. 2016;9:160. DOI: 10.1007/s12517-015-2163-2.

[21] Davenport HM, Peter LK. Field studies of atmospheric particulates concentration changes during precipitation. Atmos Environ. 1978;12:997-1008. DOI: 10.1016/0004-6981(78)90344-X.

[22] Mircea M, Stefan S, Fuzzi S. Precipitation scavenging coefficient: influence of measured aerosol and raindrop size distributions. Atmos Environ. 2000;34:5169-5174. DOI: 10.1016/S1352-2310(00)00199-0.

[23] Andronache C. Estimated variability of below-cloud aerosol removal by rainfall for observed aerosol size distributions. Atmos Chem Phys. 2003;3:131-143. DOI: 10.5194/acp-3-131-2003.

[24] Laakso L, Gronholm T, Rannik U, Kosmale M, Fiedler V, Vehkamaki H, et al. Ultrafine particle scavenging coefficients calculated from 6 years field measurements. Atmos Environ. 2003;37:3605-3613. DOI: 10.1016/S1352-2310(03)00326-1.

[25] Maria SS, Russell LM. Organic and inorganic aerosol below-cloud scavenging by suburban New Jersey precipitation. Environ Sci Technol. 2005;39(13):4793-4800. DOI: 10.1021/es0491679.

[26] Shukla JB, Sundar S, Misra AK, Naresh R. Modelling the removal of gaseous pollutants and particulate matters from the atmosphere of a city by rain: Effect of cloud. Environ Model Assess. 2008;13:255-263. DOI: $10.1007 / \mathrm{s} 10666-007-9085-7$.

[27] Kyrö E, Grönholm T, Vuollekoski H, Virkkula A, Kulmala M, Laakso L. Snow scavenging of ultrafine particles. Field measurements and parameterization. Boreal Environ Res. 2009;14:527-538.

[28] Tai APK, Mickley LJ, Jacob DJ. Correlations between fine particulate matter (PM2.5) and meteorological variables in the United States: Implications for the sensitivity of PM2.5 to climate change. Atmos Environ. 2010;44:3976-3984. DOI: 10.1016/j.atmosenv.2010.06.060.

[29] Zhang X, Huang Y, Rao R. Aerosol characteristics including fumigation effect under weak precipitation over the southeastern coast of China. J Atmos Sol-Terr Phys. 2012;84-85:25-36. DOI: 10.1016/j.jastp.2012.05.005.

[30] Seinfeld JH, Pandis SN. Atmospheric Chemistry and Physics: From Air Pollution to Climate Change. New York: Wiley, 1998.

[31] The Opole Voivodeship Inspectorate of Environment Protection. Five years assessment of air quality due to its pollutants in Opole Province. http://www.opole.pios.gov.pl/wms/Pliki/2014/ Piecioletnia_ocena_jakosci_powietrza_za_lata_2009-2013.pdf.

[32] The Opole Voivodeship Inspectorate of Environment Protection. Air quality measurement results. http://www.opole.pios.gov.pl/wms/Pliki/2014/Wyniki_pomiarow_jakosci_powietrza_2013.pdf.

[33] Castro A, Alonso-Blanco E, González-Colino M, Calvo A, Fernández-Raga M, Fraile R. Aerosol size distribution in precipitation events in León, Spain. Atmos Res. 2010;96:421-435. DOI: 10.1016/j.atmosres.2010.01.014.

[34] European Standard BS EN 12341:1999. Air quality. Determination of the PM10 fraction of suspended particulate matter. Reference method and field test procedure to demonstrate reference equivalence of measurement methods. 1999. https://shop.bsigroup.com/ProductDetail/?pid=000000000001603131.

[35] Paramonov M, Virkula A, Grönholm T, Göke S, Laakso L. Below-cloud scavenging of aerosol particles by snow at an urban site in Finland. Internati Aerosol Conf. Helsinki: August 29-September, 2010. https://www.atm.helsinki.fi/FAAR/reportseries/rs-128.pdf.

[36] Mote T, Lacke M, Shepherd J. Radar signatures of the urban effect on precipitation distribution: a case study for Atlanta, Georgia. Geophis Res Lett. 2007;34:L20710. DOI: 10.1029/2007GL031903. 
[37] Hand L, Shepherd J. An investigation of warm season spatial rainfall variability in Oklahoma City: possible linkages to urbanization and prevailing wind. J App Meteo Clim. 2009;48:251-269. DOI: 10.1175/2008JAMC2036.1.

[38] Aikawa M, Hiraki T. Washout/rainout contribution in wet deposition estimated by $0.5 \mathrm{~mm}$ precipitation sampling/analysis. 2009;43:4935-4939. DOI:10.1016/j.atmosenv.2009.07.057.

[39] Degórska A, Śnieżek T. Comparison of chemical composition of PM10 dust in urban and non-urban background. In: Emission of Polluting Substances, Study of their Characteristics and Method of Abatement. Zabrze, Poland: Institute of Environmental Engeenring Polish Academy of Sciences; 2008.

[40] Viana M, Querol X, Alastuey A, Gangoiti G, Menendez M. PM levels in the Basque Country (Northern Spain): analysis of a 5-year data record and interpretation of seasonal variations. Atmos Environ. 2003;37:2879-2891. DOI: 10.1016/S1352-2310(03)00292-9. 